2 Pittsley RA, Talaln. Neuromuscular complications of Sjogren's syndrome. In: Pfinken PJ, Bruyn GW, eds. Handbook of Clinical Neurology. Vol. 39. Amsterdam: North Holland Publishing Company. 1980:419-33.

3 Kaltreider HB, Talel N. The neuropathy of Sjogren's syndrome. Trigeminal nerve involvement. Ann Int Med 1969;70:751-62.

\section{On the mystery of multiple sclerosis}

Sir: In his excellent article, Professor McDonald, ${ }^{1}$ with admirable discretion, really leaves untouched the mystery of the origin of multiple sclerosis after citing his title as a quotation of Gowers. However, in but a few pages he summarises nicely the evidence which leads him to conclude as to the nature of multiple sclerosis. "That it is a disease produced by an environmental agent in genetically susceptible individuals in whom there is an abnormality of the immune mechanism." He then points out that, in fact, each phrase of this definition remains to be elucidated. But he does provide a description of the essential pathophysiology of the disorder with which few could cavil.

There are, though, several points in the historical evolution of the concepts elaborated by Professor McDonald that bear modification. Dawson, ${ }^{2}$ while among the earliest to related the topography of plaques to the vascular tree, did not in fact implicate a relationship with venous territories. He stated "that in the course of this study several small areas have been followed up, serially, throughout their whole extent, and I have come to the conviction that the changes appear, but do not coincide with the area of distribution of the arteries" (p. 619).

The dominant description of the vascular supply of the central nervous system at that time was that of Kadyi, ${ }^{3}$ and it was not until the work of Herren and Alexander in 1939, ${ }^{4}$ that the venous drainage of the spinal cord was well defined. With this, it became possible to show that the topography of multiple sclerosis plaques in the cord was indeed that of the venous drainage, and that the earliest lesions seemed to be perivenular (p. $163^{5}$ ). With further assessment it became clear that cerebral plaques also were not only perivascular but also perivenular (p. $\left.151^{6}\right)$.

The great periventricular plaques in the walls of the lateral ventricles so commonly seen at necropsy and also in MRI are in fact the confluence of perivenular plaques, with or without perivenous extensions into the central white matter (Dawson's "fingers"). This was demonstrated by reconstruction of such plaques, as illustrated in fig. 13 (p. $80^{6}$ ).

Periphlebitis retinae ("venous sheathing") is a similar process on the retina, with lymphocytic infiltrations about the vessel (figs 17,$18 ;$ p. $\left.154^{6}\right)$. Of course one can not speak of "plaques" without demyelination or astrocytosis, but the essential pathology seems quite similar. Tine Engell, ${ }^{7}$ found periphlebitis retinae in $15 \%$ of 135 patients hospitalised for multiple sclerosis versus $5 \%$ of 168 multiple sclerosis patients examined at a rehabilitation centre. Of 37 patients evaluated during exacerbation or rapid progression, periphlebitis retinae was present in $16(43 \%)$. I would suggest then that one might reconsider the last sentence of my work on cerebral plaques: "From the point of view of pathological anatomy, multiple sclerosis is a condition of "periphlebitis cerebrospinalis et retinalis", (p. $\left.159^{6}\right)$.

TORBEN FOG*

Bredgade 202 t.v. 1260 Copenhagen $K$ Denmark

\section{References}

1 McDonald WI. The mystery of the origin of multiple sclerosis. $J$ Neurol Neurosurg Psychiatry 1986;49:113-23.

2 Dawson JW. The histology of disseminated sclerosis. Trans $R$ Soc Edinburgh 1916;50: $517-40$.

3 Kadyi H. Über die Blutgefässe des menschlichen Rückenmarkes. Lemberg 1889.

4 Herren RY, Alexander L. Sulcal and intrinsic blood vessels of human spinal cord. Arch Neurol Psychiatry 1939;41:678.

5 Fog T. Rygmarvens Patologiske Anatomi ved Dissemineret Sclerose og Dissemineret Encephalomyelitis. Copenhagen, Munksgaardsforlag 1948.

6 Fog T. The topography of plaques in multiple sclerosis. With special reference to cerebral plaques. Acta Neurol Scand 1965;(suppl 15): $1-161$

7 Engell T. Neurological disease activity in multiple sclerosis. Acta Neurol Scand 1986;73:168-72.

*Deceased 19 April 1987.

Thoracic cord compression from metastatic prostate carcinoma with Lhermitte's "sign"

Sir: I was interested to read the report by Baldwin and Chadwick ${ }^{1}$ in which a patient with a cavernous hemangioma producing complete spinal block at the fifth thoracic level experienced Lhermitte's "sign"으 I thought the authors might be interested report of similar symptoms in anomer patient with thoracic spinal block, althomg flexion of the neck in this case produced a sensory disturbance radiating into the aurerior thighs. The description of the patieng's symptomatology is rendered vividly as the author (a neurosurgeon) described the symptoms experienced at the time he de oped spinal cord compression from pros te carcinoma. Interestingly, the level of spimal block was also at the fifth thoracic level. . is symptoms, as with their patient, disappeared after surgical decompression.

The mechanism of the particular sensāiry disturbance experienced upon neck flex by both of these patients remains speetulative. I concur with Baldwin and Chadwơk that, at least in some patients, Lhermitte's "sign" should direct investigation to possible pathology in the thoracic as well as cervical spine region.

LISA R ROGERS, 文Oे. Head, Neuro-Oncology Prog䲩m Department of Neurology Cleveland Clinic Foundakgn Cleveland, Ohio 44106屯SA

References

I Baldwin RN, Chadwick D. Lhermitte's due to thoracic cord compression. JF Neurosurg Psychiatry 1986;49:840-1.0

2 Broager B. Lhermitte's sign in thoraciç tumour. Acta Neurochir (Wein) $\leq 1928$; 41:127-35.

International Society for the Study of Bragh Edema. The Triennial Meeting will be he्]d 7-10 October 1987 in Baltimore, USA. Information may be obtained from: Program Coordinator, Office of Continuirig Education, The Johns Hopkins Medięal Institutions, Turner 22, 720 Rutlāpd Avenue, Baltimore, Maryland 21205, USA.

International Society for Adolescent Psychiatry. The 2nd International Congress will be held in Geneva, 10-13 July 19\%. Information may be obtained from: The Secretary, 2nd International Congress Adolescent Psychiatry, P.O. Box 50 CH-1211 Geneva 8, Switzerland. 